\title{
Sandra Azeredo
}

Universidade Federal de Minas Gerais

\section{Mestiçagem, igualdade e afirmação da diferença - pensando a política de cotas na universidade}

Resumo: Escrito num momento em que no Brasil a mestiçagem estava na ordem do dia, pela relação que se estabelecia entre ela e a questão das cotas nas universidades para pessoas pobres, negras e indígenas, contida no anteprojeto de reforma universitária proposto pelo Ministério da Educação, este ensaio se inspirou no trabalho de Gloria Anzaldúa no sentido de contribuir para o debate sobre a introdução de cotas, através da discussão da noção de mestiçagem, analisando a fundamentação do anteprojeto formulada pelo então ministro da Educação, Tarso Genro, e por Boaventura de Sousa Santos e quatro textos publicados na época com posições contrárias à introdução de cotas. Tomando como base o conceito de consciência mestiça de Anzaldúa, o ensaio termina por argumentar que a reforma pressupõe uma reestruturação profunda da universidade, que está em crise justamente por seu caráter excludente ao longo de sua história.

Palavras-chove: mestiçagem, igualdade, ação afirmativa, consciência mestiça.

... até porque no Brasil não se é negro impunemente... Agnaldo Farias, Catálogo de Exposição de Emanoel Araújo

All of our rational denials only deepen the suppurating puncture wound of a racialized history, past and present. Donna Haraway, "Race: Universal Donors in a Vampire Culture" button do Movimento Negro

Quem ensina sem emancipar, embrutece. E quem emancipa não tem que se preocupar com aquilo que o emancipado deve aprender. Ele aprenderá o que quiser, nada, talvez. Jacques Rancière, O mestre ignorante 
Copyright (c) 2005 by Revista Estudos Feministas

${ }^{1}$ Toda nossa negação apenas aprofunda o corte na ferida supurada de uma história racializada no passado e no presente.

2 Título da primeira parte do livro, composta por sete capítulos.

${ }^{3}$ ANZALDÚA, 1987, p. 17.

${ }^{4}$ ANZALDÚA, 1987, p. 22.
O trabalho de Gloria Anzaldúa, escrito e publicado nos Estados Unidos, propõe uma nova consciência, uma consciência mestiça, das fronteiras, uma consciência de mulher. É uma proposição de uma chicana que, como ela afirma, diferentemente das teorias de uma raça branca pura, busca a inclusão. Seu trabalho representa a conclusão de uma complexa narrativa da experiência de "atravessar fronteiras", ${ }^{2}$ em que ela conta a história das lutas da população chicana pela terra, das guerras entre mexicanos e anglos, das cercas que passaram a dividir o povo mexicano, da expropriação de suas pequenas propriedades e também de sua revolta contra a dominação que sofreu em sua própria cultura heterossexista. Diz ela:

Para uma mulher em minha cultura havia apenas três direções a seguir: a igreja, como freira, a rua, como prostituta, ou a casa, como mãe. Hoje algumas de nós têm uma quarta escolha: entrar no mundo através da educação e da carreira e nos tornarmos pessoas autônomas. Muito poucas entre nós. Como um povo da classe operária nossa atividade principal é colocar comida em nossas bocas, um teto sobre nossas cabeças e roupas em nossas costas. Educar nossos filhos e filhas está fora de alcance para a maioria de nós. ${ }^{3}$

E continua: "Não vou glorificar os aspectos de minha cultura que me prejudicaram e que me prejudicaram em nome de minha proteção". E é a partir dessa recusa que Anzaldúa se propõe a criar o próprio espaço e "fazer uma nova cultura - una cultura mestiza - com minhas próprias tábuas, meus próprios tijolos e argamassa e minha própria arquitetura feminista". ${ }^{4}$

Neste ensaio, inspiro-me no trabalho de Anzaldúa para pensar a mestiçagem no Brasil, embora estejamos nos referindo a processos diferentes, a começar pelas raças que compõem a mistura além da branca e da indígena que são comuns a ambas - a população chicana no trabalho de Anzaldúa e a população negra em meu trabalho. Como a própria Anzaldúa afirma, a negritude raramente é considerada quando uma pessoa chicana está se definindo.

Quando não desistimos, quando sabemos que somos alguém, nos chamamos mexicanos, nos referindo à raça e ancestralidade; mestizo quando afirmamos nossas duplas ancestralidades índia e espanhola (porém nós quase nunca nos apropriamos de nossa ancestralidade negra); chicana quando nos referimos ao povo politicamente consciente nascido e/ou criado nos U.S.A.; Raza quando nos referimos aos chicanos/ as; tejanos quando somos chicanos/as do Texas (a ênfase em negrito é minha). ${ }^{5}$ 


\begin{abstract}
${ }^{6}$ Estou usando o termo povo no sentido que Ihe dá Gilles Deleuze, que argumenta que povos não preexistem e que sua constituição envolve processos complexos de construção de discursos contrahegemônicos, que se opõem ao do colonizador. Como ele diz, "De certa maneira, o povo é o que falta, como dizia Paul Klee" (Deleuze, 1998, p. 157). Anzaldúa escreve que "os chicanos não sabiam que eram um povo até 1965, quando Ceasar Chaves e os camponeses se uniram e Eu sou Joaquín foi publicado e o partido da Raza Unida se formou no Texas" (ANZALDÚA, 1987, p. 63).

${ }^{7}$ Ser vizinho de porta do Império Americano certamente tem sérias conseqüências na constituição de um povo.

${ }^{8}$ Os textos de Genro estão em duas publicações recentes da UFMG e o de Santos é seu trabalho sobre "A universidade do século XXI", apresentado em Brasília em abril de 2004, no âmbito do calendário oficial de debates sobre a universidade.

${ }^{9}$ GENRO, 2005, p. 6.
\end{abstract}

${ }^{10}$ SANTOS, 2004, p. 39.

"SANTOS, 2004, p. 48.

12 SANTOS, 2004, p. 50.
Por outro lado, não há como não falar do povo negro quando se trata da mestiçagem no Brasil. Assim como aconteceu em Cuba e no resto do Caribe, a cultura negra da África nos marcou definitivamente enquanto povos. ${ }^{\circ}$ Do mesmo modo, o povo chicano é fruto da especificidade da geografia do México, que o faz vizinho dos Estados Unidos. $^{7}$

No Brasil, estamos vivendo um momento da nossa história em que a mestiçagem está na ordem do dia, pela relação que se estabelece entre ela e a questão das cotas nas universidades para pessoas pobres, negras e indígenas, o que está contido no anteprojeto de reforma universitária proposto pelo Ministério da Educação. Meu interesse aqui é contribuir para o debate sobre a introdução de cotas com a qual concordo - através da discussão da noção de mestiçagem, analisando a fundamentação do anteprojeto formulada pelo ministro da Educação, Tarso Genro, e por Boaventura de Sousa Santos e quatro textos publicados recentemente com posições contrárias à introdução de cotas. $^{8}$

\section{As cotas}

Em sua fundamentação da reforma, Genro coloca a importância da universidade pública para a realização de um projeto de nação "moderna, coesa e democrática". 9 Santos também argumenta que a reforma da universidade pública deve refletir um projeto de país que é resultado de um amplo contrato político e social. Segundo ele, "a reforma tem por objectivo central responder positivamente às demandas sociais pela democratização radical da universidade, pondo fim a uma história de exclusão de grupos sociais e seus saberes de que a universidade tem sido protagonista ao longo do tempo". ${ }^{10}$ Para Santos, na maioria dos países a discriminação tem feito do acesso à universidade "uma mistura de mérito e privilégio". ${ }^{11}$ Por isso, ele propõe que nas sociedades "onde o racismo, assumido ou não, é um facto, as discriminações raciais ou étnicas devem ser confrontadas enquanto tal com programas de acção afirmativa (cotas e outras medidas) que devem visar, não só o acesso, como também o acompanhamento, sobretudo durante os primeiros anos onde são por vezes altas as taxas de abandono". E continua: "Sem dúvida que a discriminação racial ou étnica ocorre em conjunção com a discriminação de classe, mas não pode ser reduzida a esta e deve ser objecto de medidas específicas". ${ }^{12}$

Em relação à questão do acompanhamento, Genro se refere à necessidade de preparação da universidade para receber as/os estudantes que se beneficiarão dessas 
${ }^{13}$ GENRO, 2004, p. 2.

${ }^{14}$ SANTOS, 2004, p. 53.

${ }^{15}$ SANTOS, 2004, p. 56.

${ }^{16}$ SANTOS, 2004, p. 57. ações. Segundo ele, o objetivo fundamental da universidade pública é justamente "abrir espaços para incorporar todos os cidadãos, que o queiram, no saber e no conhecimento, cumprindo também a sua função de ser uma instituição republicana de combate às desigualdades". ${ }^{3}$ Santos propõe uma "ecologia dos saberes" como parte dessa preparação da universidade para receber as/os estudantes. Segundo ele, a universidade não apenas participou da exclusão de determinados grupos, "como teorizou a sua inferioridade, uma inferioridade que estendeu aos conhecimentos produzidos pelos grupos excluídos em nome da prioridade epistemológica concedida à ciência". ${ }^{14}$ Santos vê a ecologia dos saberes como sendo
uma forma de extensão ao contrário, de fora da universidade para dentro da universidade. Consiste na promoção de diálogos entre o saber científico ou humanístico, que a universidade produz, e saberes leigos, populares, tradicionais, urbanos, camponeses, provindos de culturas não ocidentais (indígenas, de origem africana, oriental, etc.) que circulam na sociedade. ${ }^{15}$

De acordo com Santos, esse diálogo promove a cidadania ativa crítica e "serve de base à criação de comunidades epistémicas mais amplas que convertem a universidade em um espaço público de interconhecimento onde os cidadãos e os grupos sociais podem intervir sem ser exclusivamente na posição de aprendizes". ${ }^{16}$

Passemos agora às críticas feitas a esse modelo de universidade proposto por Genro e Santos. Marcus Vinicius de Freitas, professor da Faculdade de Letras da Universidade Federal de Minas Gerais, inicia sua mensagem de patrono às/aos formandas/os, reproduzida no Boletim UFMG, relatando que, "há quatro anos, uma caloura [havia caído] de pára-quedas em [sua] turma de Fernando Pessoa" por ter sido obrigada pela "delirante" reforma de currículo da Faculdade, que não tem disciplinas básicas, cujos conteúdos são idiossincráticos, que, enfim, repudia "a mínima noção de lógica e racionalidade [...] em prol do retorno à taba, à lei do mais forte, do mais esperto, do mais demagogo". Segundo ele, estudar Fernando Pessoa, "sem a devida preparação, é como ser cirurgião sem saber sequer a forma do bisturi". Freitas considera a atual reforma da universidade proposta pelo governo como sendo ainda mais delirante, uma "tsunami obscurantista", que transformará as universidades, "de centro de formação de excelência em assistentes sociais politicamente interessadas", instrumentalizadas "como braço de 
17 FREITAS, 2005, p. 2.

${ }^{18}$ VILLELA, 2005, p. 2.

${ }^{19}$ VILLELA, 2005, p. 2. propaganda de programas como o Fome Zero". Freitas, em suma, considera o projeto como sendo "inconstitucional, intervencionista, demagógico [porque as vagas não serão destinadas aos melhores alunos, mas à distribuição pelo instrumento lamentável das cotas] e xenófobo". ${ }^{17}$

Outro posicionamento contrário ao projeto de reforma do governo é de João Baptista Villela, professor titular da Faculdade de Direito da Universidade Federal de Minas Gerais, que defende a universidade como "o lugar ímpar de aplicação às formas superiores do saber", que está sendo ameaçado, entre outras coisas, pela idéia de cotas para afrodescendentes ou egressos do ensino público. Segundo ele,

criar distinções fundadas na etnia ou em condições sociais e econômicas é um modo cínico e arrogante de legitimar preconceitos, porque perpetua a inferioridade do desvalido (sic). Ao se afastar do princípio do mérito para se pôr a serviço do imediato nivelamento social, a universidade [...] rompe com suas origens. Trai o seu destino. E acaba por agravar o próprio desequilíbrio social pelo fato de que seus egressos não terão adquirido o poder de intervir sobre a realidade, modificando-a para melhor. ${ }^{18}$

Para Villela, "a universalização indiscriminada do ensino universitário, mesmo sem o sistema de cotas, ao invés de criar uma sociedade universalmente elitária, conduz ao que a crítica da pedagogia fácil chamou de akademisches Proletariat: um dos bons roteiros para o desemprego e a indigência". ${ }^{19}$ Ou seja, para ele, a universidade deve ser o espaço reservado a apenas uma parte da população, a que se considera "a melhor".

Embora esses dois depoimentos não tratem da questão da mestiçagem, eles nos interessam pela ênfase na exclusão, representando assim um contraponto da consciência mestiça, inclusiva de Anzaldúa. Os dois posicionamentos seguintes, por outro lado, se apóiam explicitamente na noção de mestiçagem para fundamentar sua oposição à política de cotas do governo. Yvonne Maggie, professora de Antropologia da Universidade Federal do Rio de Janeiro, em artigo publicado em O Globo e reproduzido no Boletim da UFMG, lamenta que a reforma traga para o Brasil, "que até hoje tem se constituído em um país de legislação a-racial", a atribuição de direitos "a partir da definição obrigatória em uma das categorias do IBGE". Segundo ela,

As cotas raciais ao serem introduzidas nos fazem sair necessariamente de um país que se queria misturado 
${ }^{20}$ MAGGIE, 2005, p. 2.

${ }^{21}$ MAGGIE, 2005, p. 2.

${ }^{22}$ VIANNA, 2004, p. 4-6. e onde a cor dos indivíduos não deveria influenciar a vida do cidadão para entrar no mundo dividido entre "raças". Ou se é negro ou não se é negro legalmente.

Será que o ministro e seus assessores estão pensando nas conseqüências dessa mudança tão radical, esquecendo seus receios iniciais [que a reparação para negros nos problemas social e racial fundidos não pode permitir que um negro pobre concorra com um branco pobre e um exclua o outro]? Será que os nossos representantes se dão conta de que essa mudança, aparentemente pequena, é um passo muito grande para a criação de um país dividido entre brancos e negros? ${ }^{20}$

Maggie, com base em sua pesquisa nas escolas públicas do Rio de Janeiro, conclui com um mau presságio de um duelo futuro por vagas entre os legalmente negros e os legalmente brancos, na medida em que ela vê a introdução do sistema de cotas como colocando a disputa por vagas "nas costas daqueles mais pobres que estão estudando em escolas públicas de qualidade duvidosa". ${ }^{21}$

Outro antropólogo, Hermano Vianna, escreve no caderno Mais! um artigo sobre "a mestiçagem fora de lugar". ${ }^{22} \mathrm{O}$ discurso de Vianna merece uma análise mais cuidadosa, pois ele de certa forma sintetiza as posições contrárias às cotas e a defesa da mestiçagem, utilizando uma linguagem que é um misto de deboche, ironia e provocação, o que torna seu texto bastante interessante. Vianna "pede licença" para entrar no "assunto delicado" das cotas, contando sua experiência sufocante com o "politicamente correto" na década de 1990 em Chicago, que ele viveu como um estrangeiro (na verdade, foi classificado como hispânico, "coisa que nunca pens[ou] ser, apesar de adorar a cultura dos chicanos e portoriquenhos da cidade"). Vianna conta como viveu as experiências de introdução de cotas na Universidade Northwestern. Segundo ele, o aumento do número de negros na pós-graduação do departamento de sociologia trouxe

uma perene ameaça velada de crise, como se a qualquer momento pudesse surgir a acusação de que quem entrou por meio de processos especiais não tem méritos suficientes para estar ali ou que o próprio aluno que sabe estar ali por "ação afirmativa" acabe, mesmo sem querer, se sentindo e atuando como penetra numa cerimônia para a qual não foi totalmente convidado. É claro que todo mundo no departamento sabe desconstruir a questão de mérito individual etc. - mas tanta sofisticação ideológica e militância política antiracista não tornam a situação totalmente confortável. 
${ }^{23}$ VIANNA, 2004, p. 5.

${ }^{25}$ Citado por VIANNA, 2004, p. 6.

Pelo contrário: a situação tem mais chances de se tornar paralisante. Foi o que aconteceu logo no primeiro ano. No início de cada curso, quando o professor apresentava a bibliografia, os estudantes negros reclamavam que não havia um número justo de afroamericanos entre os autores dos textos recomendados. Alguns cursos pararam naquele debate, que não deixava de ser muito interessante, apesar de adiar 0 início da matéria em que todo mundo tinha se inscrito. ${ }^{23}$

Outra experiência narrada por Vianna se deu em um curso em que uma aluna descendente de índios disparou a chorar quando contou que nunca tinha usado sua identidade étnica para conseguir vagas de estudo ou de trabalho. Vianna conta que "todos ficamos em silêncio, esperando o choro passar". Em seu discurso narrando essas duas experiências fica evidente a antipatia de Vianna pelas cotas, mas ele diz que está disposto a aceitar o desafio de continuar a lutar contra o racismo, como sempre fez, até pelo caminho das cotas, já que é este o que está sendo escolhido pelo Brasil agora. Porém, confessa, "talvez pela última vez", sua "diferença fundamental em relação aos advogados das cotas":

gosto de mestiçagem, gosto também da idéia de que até agora o melhor do Brasil foi produzido sobretudo pela valorização da mestiçagem. Nunca achei que valorizar a mestiçagem fosse sinônimo de defender a idéia de que vivemos numa democracia racial. Entendo até que o elogio da mestiçagem possa ser usado ou tenha sido usado por algum ignorante (entre eles não estava Gilberto Freyre) que queria provar a inexistência de racismo no Brasil. Mas nunca foi como lidei com o assunto: para mim a valorização da mestiçagem é uma das armas mais poderosas para serem usadas no combate anti-racista, no Brasil ou fora do Brasil. ${ }^{24}$

Vianna argumenta que no Brasil houve "uma experiência única de valorização da mestiçagem, que não foi levada às suas últimas libertárias conseqüências". E fundamenta seu argumento com o poema "Americanos", de Caetano Veloso:

Para os americanos branco é branco, preto é preto (e a mulata não é a tal), bicha é bicha, macho é macho, mulher é mulher, e dinheiro é dinheiro. E assim ganhamse, barganham-se, perdem-se, concedem-se, conquistam-se direitos, enquanto que aqui em baixo a indefinição é o regime e dançamos com uma graça cujo segredo nem eu mesmo sei. ${ }^{25}$

Para Vianna, se adotarmos as cotas, perde força uma alternativa indefinida para o mundo. Porém, ele lembra que "o movimento de valorização da mestiçagem - ou da 
${ }^{26}$ VIANNA, 2004, p. 6.

27 VIANNA, 2004, p. 6.

\footnotetext{
${ }^{28}$ A esse respeito, ver o artigo de James CLIFFORD, 1984, sobre "alegoria etnográfica".

29 HARAWAY, 1997.
}

hibridização ou da crioulização (para usar termos mais politicamente corretos) - vai continuar vivendo razoavelmente bem e talvez florescer da maneira que eu imagino que deveria acontecer no Brasil e em outros lugares". ${ }^{26}$ Dá como exemplos desse florescimento o livromanifesto Elogio da crioulidade, lançado em 1989 na França, que propõe uma leitura "pós-negritude e pósEdouard Glissant para o assunto", e a revista de moda e comportamento Trace, editada em Nova York e Londres, cujas capas mostram mestiços das mais variadas combinações étnicas e cujos artigos repetem o elogio da diferença. Vianna finaliza sua defesa da mestiçagem lembrando que seus novos pensadores dão ênfase na mistura mais como processo do que produto "e também no caráter não-sintético do mestiço [...] no qual as diferenças não se desfazem, mas enriquecem o todo por permanecerem diferentes ocupando o mesmo espaço". Busca fundamentação para isso em Gilberto Freyre (a quem chama de "autor 'proibido'”), para quem "a mestiçagem é um precário equilíbrio de antagonismos", e, depois de apelar para que não se chame "todo pensamento anticotas de pensamento racista", pois isso seria "uma simplificação medonha!", pontifica:

Cota definitivamente não se dá bem com mestiços! Se o Brasil com isso se transformar mesmo numa verdadeira democracia racial, não teremos perdido grande coisa [...] Ou teremos? Afinal, não somos todos (nós seres humanos), desde sempre e para sempre, culturalmente e "racialmente", mestiços?27

\section{Mestiçagem}

Embora a visão de Vianna sobre a mestiçagem seja interessante por considerá-la como um processo que não elimina a diferença, ela me incomoda profundamente por sua negação sistemática do fato da desigualdade entre as raças que a compõem. O final apoteótico de seu artigo nos colocando "desde sempre e para sempre" como mestiços, lembra o gesto antropológico de Lévy-Strauss em Tristes tropiques no final de seu capítulo sobre os Nambikwara, quando, em sua busca de formas elementares de coletividade, diz que ali encontrara "apenas homens". ${ }^{28}$ Meu incômodo também me remeteu ao capítulo de Donna Haraway ${ }^{29}$ sobre raça, em que ela se sente desconfortável - e mesmo assustada - com a capa da revista Time, no número especial sobre imigração, no outono de 1993, que mostra o retrato de uma mulher montado (morphed) pelo computador a partir da mistura de várias raças, descrita como "uma notável antecipação da [...] Nova Face da 
30 HARAWAY, 1997, p. 264.

América". Vale a pena reproduzir as palavras de Haraway expressando seu desconforto com o texto produzido pela revista Time:

Toda a história sangrenta contida na palavra miscigenação está faltando no sanitizado termo morphing. O multiculturalismo e a mistura racial na revista Time são menos conquistas em contraste com os presságios de tanta dor do que uma receita de como ser inocentemente arrebatado de um tempo mundano para um tempo de redenção. A resoluta ausência de história, do corpo carnoso que sangra é o que me assusta. A reconfirmação da Imagem Sagrada do Mesmo, mais uma vez sob o signo da diferença, é o que ameaça o renascimento nacional. Quero algo muito mais bagunçado, mais perigoso, mais denso, e mais gratificante da esperança do multiculturalismo. Para se chegar a essa espécie de parto da saúde reprodutiva nacional vai ser preciso lidar com poder, privilégio, exclusão, e exploração racial e sexualizada do passado e do presente. Desconfio que a nação vai ter que engolir o óleo de rícino da sóbria responsabilidade por tal sexo racializado antes que morphing pareça divertido para a maioria de seus/suas cidadãos/ãs. ${ }^{30}$

É essa falta de história - das "histórias de dominação e resistência", como diz Haraway, citando Claudia Castañeda, das histórias que Anzaldúa conta sobre a dor que significa estar na fronteira entre três povos até chegar à sua proposição de uma consciência mestiça - que me incomodou tanto no texto de Maggie e de Vianna. Tudo se passa como se a miscigenação não tivesse implicado dor, rejeição, exclusão, exploração, e morte neste "país que se queria misturado e onde a cor do indivíduo não deveria influenciar a vida do cidadão". Independentemente dessas boas intenções, sabemos que a cor influenciou, sim, e continua a influenciar, a vida de mulheres, homens e crianças neste país. Entre milhares de exemplos, há o assassinato recente do jovem dentista negro pela polícia. Essa 'influência' da cor na vida das pessoas pretas está lá, em uma outra letra de Caetano Veloso, Haiti:

111 presos indefesos, mas presos são quase todos pretos Ou quase pretos, ou quase brancos quase pretos de tão pobres

E pobres são como podres e todos sabem como se tratam os

Pretos.

E a mulata da outra letra de Caetano? Será que é mesmo a tal, como sugere Vianna? Conforme mostram os trabalhos de Mariza Correa e de Sônia Giacomini, ela se 
${ }^{31}$ GIACOMINI, 1992.

${ }^{32}$ GIACOMINI, 1992, p. 244.

${ }^{33}$ GIACOMINI, 1992, p. 223.

${ }^{34}$ CORREA, 1996, p. 49. constrói através da dupla dominação de raça e gênero. Em seu estudo no Curso de Formação Profissional de Mulatas no Rio de Janeiro, Giacomini mostra que as alunas, que moram na Zona Norte ou nos subúrbios do Rio, buscam um caminho que lhes permita sair de empregos como o de empregada doméstica e fazer carreira de sucesso e estrelato. ${ }^{31}$ Segundo Giacomini, os promotores do curso vêem o espaço que abrem para as mulheres que têm a cor de mulata como sendo "uma extraordinária contribuição à reafirmação da democracia racial brasileira e uma verdadeira obra de promoção dos negros", no entanto, através da fala de uma das alunas, este espaço que se abre para a mulata se dá em uma situação em que outros espaços profissionais se caracterizam por excluí-la: "A oportunidade aqui é para as mulatas, porque as brancas têm outras carreiras para fazer". ${ }^{32}$ É justamente nessa separação de espaços para brancas e não brancas que se coloca a questão de gênero, pois é parte da carreira da mulata participar de "rituais de sedução do homem branco (no caso, o gringo)", o que levanta a perene possibilidade de ela ocupar o lugar da prostituta, que não é o lugar da mãe e esposa, reservado para a mulher branca. Esse lugar da mulata como a outra da esposa e mãe aparece mais definido em um outro trabalho de Giacomini, em que ela estuda "A Noite da Beleza Negra" e o "Show de Mulatas", mostrando que neste último a mulata está só. "O seu parceiro virtual é o branco, que pode deixar a família em lugar seguro, que pode deixar a companheira (se é que foi acompanhado à casa de espetáculo) na mesa, para subir ao palco onde se celebra a união entre as raças". ${ }^{33}$

Correa sintetiza sua teorização sobre a invenção da mulata indicando que a construção desta
contribui, no âmbito das classificações raciais, para expor a contradição entre a afirmação de nossa democracia racial e a flagrante desigualdade social entre brancos e não brancos em nosso país: como "mulato" é uma categoria extremamente ambígua e fluida, ao destacar dela a mulata que é a tal, parece resolver-se esta contradição, como se se criasse um terceiro termo entre os termos polares Branco e Negro. Mas, no âmbito das classificações de gênero, ao encarnar de maneira tão explícita o desejo do Masculino Branco, a mulata também revela a rejeição que essa encarnação esconde: a rejeição à negra preta. $^{34}$

Correa agrega à sua análise uma nota final, em que sugere que a figura da mulata possa estar sendo "culturalmente desconstruída", sendo um sinal disso a 
${ }^{35}$ Acho importante assinalar que nesse trabalho Correa usa como epígrafe uma parte dos versos de "Americanos" utilizados por Vianna, e, em uma nota, o cita como sendo autor de "uma fina análise da criação do samba como expressão do 'projeto mestiço' brasileiro" (CORREA, 1996, p. 39).

${ }^{36}$ TADEI, 2002, p. 3.
${ }^{37}$ RAMOS, citado em CONSORTE, 1997 , p. 29. palavra mulata não ter aparecido em chamadas da Rede Globo sobre o carnaval. ${ }^{35} \mathrm{O}$ que me parece mais importante, entretanto, é a coincidência que se pode encontrar em sua análise e na de Giacomini no que diz respeito à articulação da dominação de gênero e raça na construção da mulata no Brasil. Se realmente essa figura está sendo desconstruída, será necessário não perder de vista tal articulação.

Os estudos de Correa e Giacomini mostram que a construção da mulata, que aparentemente valoriza a contribuição da raça negra para a mestiçagem no Brasil a mulata é a tal -, apenas confirma o argumento de Emanuel Tadei sobre a mestiçagem como dispositivo do poder, no sentido dado por Foucault, isto é, como "um conjunto de saberes e de estratégias de poder que atua sobre nossa identidade nacional, tendo por objetivo integrar e tornar dóceis as etnias que estão na raiz de nossa nacionalidade (no caso os indígenas do continente e os negros africanos)". ${ }^{36}$ Tadei escreve que na época da colonização a idéia era disseminar o sangue e a cultura europeus de modo a produzir uma nacionalidade brasileira que se tornaria cada vez mais branca. As pessoas nascidas nesse processo de mestiçagem - os mestiços e mulatos eram considerados como estando em um estágio intermediário entre o bom (europeu) e o mau (negros e indígenas). Tadei argumenta que o discurso racial brasileiro foi construído nesse projeto de modernização e constituição de uma identidade nacional que usou a mestiçagem como uma forma de impor a cultura européia branca como a ideal. A argumentação de Tadei é confirmada pelo estudo de Josildeth Consorte sobre a introdução do multiculturalismo no Brasil na década de 1950 e seus efeitos no projeto educacional de proteger a unidade nacional. Consorte mostra como as escolas não respeitavam a diversidade cultural no uso que faziam de duas estratégias: o abrasileiramento dos descendentes de imigrantes e a erradicação de todas as tradições culturais de origem africana, consideradas como sendo de uma mentalidade pré-lógica, conforme o discurso de Arthur Ramos:

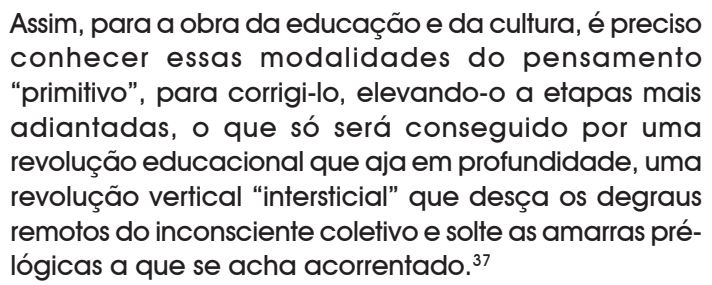


${ }^{38}$ CONSORTE, 1997, p. 29.

${ }^{39}$ No início dos anos 1990, em palestra proferida durante o lançamento de um livro em Belo Horizonte, Arnaldo Jabor afirmou que nós brasileiros tínhamos sorte de japoneses, italianos e alemães terem imigrado para o Brasil, do contrário, hoje estaríamos mergulhados "na mais profunda África". Eu fui a única a me levantar e sair da sala lotada e tenho que admitir que me senti intimidada pela ausência de reação das pessoas a essa manifestação de racismo tão evidente. Como não consegui me expressar no momento, alguns dias depois enviei a ele uma carta, tentando conversar sobre o que tinha acontecido, porém ele nunca me respondeu. Certamente não terá nem lido a carta.

${ }^{40} \mathrm{FRY}, 1982$, p. 53.
Segundo Consorte, o que esse discurso apresenta "de modo tão elegante [...] faz-se presente de maneira bastante violenta, no cotidiano destas populações, por meio de uma perseguição sistemática orquestrada pelo estado brasileiro a todas as suas formas organizadas de expressão (candomblé, capoeira, roda de samba, batucada etc.)". ${ }^{38}$ Se, por um lado, é evidente - e maravilhoso! - que o Estado não foi bem-sucedido na erradicação da tradição africana, por outro lado, é também evidente - e lamentável! - que conseguiu impor a superioridade da cultura européia branca. ${ }^{39}$ Nesse jogo de erradicação e imposição continua a acontecer o processo de mestiçagem brasileira, no qual, como muito bem mostra Peter Fry, "a conversão de símbolos étnicos em símbolos nacionais não apenas oculta uma situação de dominação racial mas torna muito mais difícil a tarefa de denunciá-la. [...] Agora que o candomblé e o samba são considerados chiques e respeitáveis, perderam o poder que antes possuíam". ${ }^{40}$ Referindo-se à diferença entre a feijoada, prato nacional do Brasil, e o soul food, prato típico de grupos negros nos Estados Unidos, Fry toca em uma questão importante para compreendermos a mestiçagem, que é a questão da pluralidade e da não-assimilação da diferença em uma identidade única e homogênea.

\section{Igualdade, identidade e diferença}

Kabengele Munanga distingue duas lógicas antiracistas: a primeira, que ele chama de "individualuniversalista", prescreve a mistura universal e é representada pela perspectiva integracionista; e a segunda, chamada de "tradicional-comunitarista", baseia-se na exigência dos direitos à diferença, criticando a integração pura e simples, pois ela é unilateral, exigindo do negro tornar-se branco. Munanga identifica o discurso anti-racista brasileiro como se enquadrando na perspectiva integracionista, opondose a qualquer busca de identidade por parte dos negros. Munanga, por outro lado, defende

a idéia da busca e da construção de uma identidade afrobrasileira do ponto de vista político e não cultural, no sentido de tomada de consciência de um segmento étnico-racial excluído da participação na sociedade, para a qual contribuiu economicamente, com trabalho gratuito como escravo, e também culturalmente, em todos os tempos na história do Brasil.

Um projeto nacional de construção de uma verdadeira democracia não pode ignorar a diversidade e as identidades múltiplas que compõem o mosaico cultural brasileiro. Um tal projeto não pode também ignorar o 
${ }^{41}$ MUNANGA, 1994, p. 187.

${ }^{42}$ RANCIÈRE, 2002, p. 14.

${ }^{43}$ RANCIÈRE, 1996b, p. 372.

${ }^{44}$ RANCIÈRE, 1996a, p. 61.

${ }^{45}$ RANCIÈRE, 1996b, p. 373.

${ }^{46}$ RANCIÈRE, 1996b, p. 375. fato de que, além das diferenças, somos semelhantes, e que o medo dos racistas está justamente na aceitação das semelhanças que fazem de nós seres capazes de exercer todas as atividades e não apenas aquelas prescritas pelas diferenças. ${ }^{41}$

Esse medo de aceitar as semelhanças de que nos fala Munanga está contido na idéia de igualdade, que Jacques Rancière considera como sendo o único princípio da política. No prefácio da edição brasileira de seu livro $O$ mestre ignorante, Rancière escreve que "a igualdade é fundamental e ausente, ela é atual e intempestiva, sempre dependendo da iniciativa de indivíduos e grupos que, contra o curso natural das coisas, assumem o risco de verificá-la, de inventar as formas, individuais ou coletivas, de sua verificação". ${ }^{42}$ Para Rancière, a igualdade não existe diretamente na ordem social. Ela se manifesta apenas através do dissenso, que significa "uma perturbação do sensível, uma modificação singular do que é visível, dizível, contável". ${ }^{43}$ Para Rancière, o dissenso e o desentendimento constituem a lógica que caracteriza a atividade e a racionalidade da política. O desentendimento refere-se ao conflito entre duas pessoas que usam a mesma palavra mas não entendem a mesma coisa. Segundo Rancière, "a querela não tem por objeto os conteúdos de linguagem mais ou menos transparentes ou opacos. Incide sobre a consideração dos seres falantes como tais". ${ }^{44}$ O problema para ele é saber se os sujeitos que participam da conversa falam ou apenas produzem ruído. Na filosofia política de Aristóteles o uso de palavras para se comunicar definia o homem (sic) como um animal político em contraste com outros animais que produziam apenas ruídos. Mas, Rancière pergunta, como reconhecemos como discurso o ruído que o animal faz diante de nós com sua boca? Esse reconhecimento não é natural, ele pressupõe uma subversão da ordem normal das coisas. Nós nos recusamos a ouvir palavras saídas da boca de alguém que não consideramos como pertencendo à comunidade política. ${ }^{45}$ A oposição estabelecida por Aristóteles entre a ordem política e a ordem doméstica negava o acesso das mulheres e dos escravos à ordem política. Rancière argumenta que a mudança dessa lógica não implicava apenas que as mulheres ocupassem o espaço público, mas era preciso a construção de uma relação entre os dois mundos em uma cena em que o princípio de igualdade que se restringia às pessoas no espaço público se estendesse para ser aplicado aos dois mundos em uma discussão de um objeto comum com pessoas que não consideravam as mulheres como pares nessa discussão. ${ }^{46}$ 
${ }^{47}$ MOUFFE, 1999a, p. 34.

${ }^{48}$ MOUFFE, 1999a, p. 42.

${ }^{49}$ MOUFFE, 1999b, p. 271.
Em relação a esses sujeitos coletivos que são as "mulheres", Chantal Mouffe considera que as perguntas centrais sejam
como se constrói a categoria "mulher" como tal, dentro de diferentes discursos?, como se transforma a diferença sexual em uma distinção pertinente dentro das relações sociais?, e, como se constroem relações de subordinação através dessa distinção? Todo o falso dilema da igualdade versus a diferença cai, desde o momento em que já não temos uma entidade homogênea "mulher" confrontada com outra entidade homogênea "homem", mas uma multiplicidade de relações sociais nas quais a diferença sexual está construída sempre de diversos modos, e onde a luta contra a subordinação tem que ser estabelecida de formas específicas e diferenciais. ${ }^{47}$

Dentro de uma concepção democrática radical de cidadania, ela propõe construir "uma identidade política coletiva articulada mediante o princípio de equivalência democrática". ${ }^{48}$ Mouffe argumenta que é preciso perceber o "caráter improvável e incerto" da democracia. Para ela, a democracia
é algo frágil, que nunca se adquire definitivamente e constitui uma conquista que sempre há que defender. A tarefa de uma política democrática não é eliminar as paixões ou relegá-las à esfera privada para possibilitar um consenso racional, mas mobilizar essas paixões e colocá-las em cena segundo dispositivos agonísticos que favorecerão o respeito ao pluralismo. Em lugar de representar um perigo para a democracia, o enfrentamento agonístico na verdade é sua própria condição de existência. ${ }^{49}$

Voltemos agora aos quatro textos detratores da política de cotas. O que há de comum entre eles é a incapacidade de pensar a mudança da universidade, a necessidade de ela se preparar para receber pessoas que ela mesma tem excluído, em outras palavras, de pensar a sua própria mudança como parte importante do seu processo de transformação. Imaginam que o curso de Fernando Pessoa vai continuar sendo dado da mesma forma, exigindo uma "devida preparação", equivalente à preparação de um cirurgião que precisa conhecer a técnica de lidar com o bisturi, que as bibliografias dos cursos podem continuar sem incluir suficiente número de autores e autoras de origem africana, que a universidade vai continuar definindo - sem ouvir os grupos excluídos - o que são "as formas superiores do saber", os critérios que definem a/o melhor aluna/o, e quais são as formas de modificar a realidade "para melhor". Enfim, nesses textos a 
${ }^{50}$ FREIRE et alii, 1991, p. 36.

${ }^{51}$ FREIRE et alii, 1991, p. 26. universidade aparece como imutável, inclusive colocando fora dela a disputa por vagas - "nas costas dos mais pobres" - sem ter que prestar contas de sua responsabilidade no processo. E, o que é pior, colocando-se tão inflexível em sua recusa de se transformar, que os/as estudantes vão se sentir como penetras em uma cerimônia para a qual não foram totalmente convidados/as!

Mas é claro que não pode ser assim! Como mostram os textos de Genro e Santos, a reforma pressupõe uma reestruturação profunda da universidade, que está em crise justamente por seu caráter excludente ao longo de sua história. Seguindo as práticas libertárias de Enrique PichónRivière e Paulo Freire, vamos ter que repensar nosso sistema educacional, esse "sistema de compartimentos sucessivos, [...] onde só se aprende o suficiente para passar para o estágio seguinte; e se a grande maioria não passa, é problema dela". ${ }^{50}$ Vamos ter que romper "com a dissociação hierárquica entre alguém que supostamente sabe e ensina e outro que supostamente ignora e aprende". ${ }^{51}$ Enfim, a universidade vai ter que inventar formas de verificar a igualdade, levando a sério o argumento central de Rancière em seu estudo do mestre ignorante:

O que pode, essencialmente, um emancipado é ser emancipador: fornecer, não a chave do saber, mas a consciência daquilo que pode uma inteligência, quando ela se considera como igual a qualquer outra e considera qualquer outra como igual à sua.

A emancipação é a consciência dessa igualdade, dessa reciprocidade que, somente ela, permite que a inteligência se atualize pela verificação. $O$ que embrutece o povo não é a falta de instrução, mas a crença na inferioridade de sua inteligência. E o que embrutece os "inferiores" embrutece, ao mesmo tempo, os "superiores". Pois só verifica sua inteligência aquele que fala a um semelhante, capaz de verificar a igualdade das duas inteligências. ${ }^{52}$

\section{A consciência mestiça}

Quando volta à sua terra natal, Anzaldúa anda pela escola primária - outrora segregada - onde estudou, e se lembra de como ela e os/as colegas tinham sido punidos/ as por serem mexicanos/as. Ela conta também como, quando foi ensinar inglês para estudantes chicanas/os no ginásio e tentou incluir textos com trabalhos de autores/as chicanos/as, foi punida pela diretoria da escola, que a proibiu de agir daquela forma. E como, mais tarde, durante seus estudos para o doutorado, teve que brigar com vários 
orientadores para conseguir que a literatura chicana fosse incluída como uma área de seus estudos. Anzaldúa não esquece essa discriminação, nem o desespero e a dor vividos por sua gente - "linchamentos, incêndios, estupros, pilhagens" -, e por isso sua proposta de uma consciência mestiça é inclusiva e pressupõe a afirmação da diferença, a vocalização das necessidades próprias do povo chicano e a luta.

Vamos ter que sair da margem oposta e de algum modo agir - não simplesmente reagir - para cicatrizar o corte (feito com aquele bisturi da aula de Fernando Pessoa?) na ferida supurada de nossa história racializada do passado e do presente. Para isso, vamos ter que achar o nosso racismo, procurar onde o guardamos e conversar sobre ele.

Olhando as fotos das/os bolsistas no cartaz do programa de ação afirmativa para a pós-graduação da Fundação Ford, na porta de meu gabinete, não vejo um Brasil dividido entre brancos e pretos. Essas fotos contrastam gritantemente com a foto higienizada da "nova face da América" representada pela mulher na capa da revista Time. E penso no enfrentamento agonístico que é a condição da existência da democracia. Imagino os perigos e a bagunça que vamos ter que enfrentar nas universidades com a introdução da política de cotas, sentindo uma grande satisfação de finalmente estarmos 'aqui embaixo' começando a desmascarar o segredo da graça de dançar em um regime de indefinição, que tem machucado e destruído tanta gente no Brasil.

\section{Referências bibliográficas}

ANZALDÚA, Gloria. Borderlands/La Frontera: The New Mestiza. San Francisco: Aunt Lute Book Press, 1987.

CLIFFORD, James. "On Ethnographic Allegory". In: CLIFFORD, James, and MARCUS, George (eds.). Writing Culture: The Poetics and Politics of Ethnography. Berkeley, Los Angeles: University of California Press, 1984. p. 98-121.

CONSORTE, Josildeth. "Culturalismo e educação nos anos 50: o desafio da diversidade". Cadernos Cedes, ano XVIII, n. 43, p. 26-37, dez. 1997.

CORREA, Mariza. "Sobre a invenção da mulata". Cadernos Pagu, n. 6-7, p. 35-50, 1996.

DELEUZE, Gilles. Conversações 1972-1990. Trad. Peter Pál Pelbart. 2. reimpressão. São Paulo: Editora 34, 1998.

FARIAS, Agnaldo. "Emanoel Araújo". In: ARAÚJO, Emanoel. Relevos e esculturas. Belo Horizonte, maio 2005. Catálogo de exposição. Galeria Murilo Castro.

FREIRE, Paulo et alii. O processo educativo segundo Paulo Freire e Pichón-Rivière. 3. ed. Petrópolis: Editora Vozes, 1991. Seminário promovido e coordenado pelo Instituto PichonRivière de São Paulo.

FREITAS, Marcus Vinicius. "Onda obscurantista". Boletim UFMG, 10 mar. 2005. 
FRY, Peter. "Feijoada e 'soul food': notas sobre a manipulação de símbolos étnicos e nacionais". In: Para inglês ver: identidade e política na cultura brasileira. Rio de Janeiro: Zahar Editores, 1982. p.47-53.

GENRO, Tarso. "Cotas, República e populismo". Boletim UFMG, 15 jul. 2004. Reproduzido do Jornal do Brasil, 26 jun. 2004.

"A Universidade reflete a ambigüidade brasileira". Diversa, n. 6, p. 5-9, mar. 2005. Entrevista.

GIACOMINI, Sônia. "Aprendendo a ser mulata: um estudo sobre a identidade da mulata professional". In: COSTA, Albertina; BRUSCHINI, Cristina (Orgs.). Entre a virtude e o pecado. Rio de Janeiro: Rosa dos Tempos; São Paulo: Fundação Carlos Chagas, 1992. p. 213 245.

"Beleza mulata e beleza negra". Revista Estudos Feministas, número especial, p. 217-227, 2. sem. 1994.

HARAWAY, Donna. "Race: Universal Donors in a Vampire Culture: It's all in the Family. Biological Kinship Categories in the Twentieth-Century United States." In: Modest_Witness@Second_Millenium.FemaleMan@_Meets_OncoMouse: Feminism and Technoscience. New York London: Routledge, 1997. p. 213-265.

MAGGIE, Yvonne. "Em breve, um país dividido". Boletim UFMG, 13 jan. 2005. Reproduzido de O Globo, 27 dez. 2004.

MOUFFE, Chantal. "Feminismo, cidadania e política democrática radical". Trad. Hortensia Moreno. Debate Feminista, Brasil, México, Edição Especial (Cidadania e Feminismo), p. 29-47, 1999a.

"Por uma política de identidade nômade". Trad. Mónica Mansour. Debate Feminista, Brasil, México, Edição Especial (Cidadania e Feminismo), p. 266-275, 1999b.

MUNANGA, Kabengele. "Identidade, cidadania e democracia: algumas reflexões sobre os discursos anti-racistas no Brasil". In: SPINK, Mary Jane (Org.). A cidadania em construção: uma reflexão transdisciplinar. São Paulo: Cortez, 1994. p. 177-188.

RANCIÈRE, Jacques. O desentendimento: política e filosofia. Tradução: Ângela Leite Lopes. São Paulo: Editora 34, 1996a.

. "O dissenso." In: NOVAES, Adauto (Org.). A crise da razão. São Paulo: Companhia das Letras, 1996b. p. 367-382.

O mestre ignorante: cinco lições sobre a emancipação intelectual. Belo Horizonte: Autêntica, 2002.

SANTOS, Boaventura de Sousa. A universidade do século XXI: para uma reforma democrática e emancipatória da universidade. Brasília, 2004. Disponível em:

http://www.ces.fe.uc.pt/bss/documentos/auniversidadedosecXXI.pdf. Trabalho apresentado em Brasília, em abril de 2004, no âmbito do calendário oficial de debates sobre a universidade.

TADEI, Emanuel. "A mestiçagem enquanto um dispositivo de poder e a constituição de nossa identidade nacional". Psicologia Ciência e Profissão, v. 22, n. 4, p. 2-13, 2002.

VIANNA, Hermano. "Mestiçagem fora do lugar". Folha de S. Paulo, 27 jun. 2004. Caderno Mais!, p. 4-6.

VILLELA, João Baptista. "Universidade, moeda de troca?". Boletim UFMG, 5 maio 2005. 
[Recebido em junho de 2005 e aceito para publicação em agosto de 2005]

\begin{abstract}
Miscegenation, Equality and Asserting Differences: Thinking on Quota Policies in the University Abstract: This essay was written during the intense debate in Brazil around the introduction of affirmative action in the public universities according to a project proposed by the Ministry of Education. Inspired in the work of Gloria Anzaldúa, this article contributes to the debate by discussing the notion of miscegenation. The essay analyzes some texts that argue in favor of the Ministry's project, as well texts that present a dissenting view. Taking as its point of departure Anzaldúa's concept of consciencia mestiza, the essay contends that to introduce a project of affirmative action in the public university system in Brazil requires a radical restructuring of the university, since the crises that confronts this institution emanates from its exclusionary practices. Key Words: miscegenation, equality, affirmative action, consciencia mestiza.
\end{abstract}

